\title{
LA TELEVISIÓN COMUNITARIA EN EL ORIENTE ANTIOQUEÑO. UN EJERCICIO DE CONSTRUCCIÓN DE TEJIDO SOCIAL Y PAZ. ${ }^{1}$
}

\section{THE COMMUNITY TELEVISION SYSTEM IN THE EASTERN REGION IN ANTIOQUIA. AN EXERCISE OF CONSTRUCTION OF THE SOCIAL FABRIC AND PEACE.}

\author{
Recibido: Enero 2014 $\quad$ Revisado: Marzo 2014 Aceptado: 1 de Mayo de 2014 \\ Por: Hilber Henao Fierro ${ }^{1}$, Jhon Fredy Vergara Vélez ${ }^{2}$, \\ Emmanuel Adalberto Ortiz ${ }^{3}$.
}

\section{RESUMEN.}

El presente artículo resultado de investigación, expone las diversas realidades que atraviesan los canales comunitarios del Oriente Antioqueño (Colombia). Para presentar los resultados el texto relaciona tres momentos: primero, aspectos jurídicos que en Colombia rigen la Televisión Comunitaria, normativas que ha regido a la televisión pública en el país y sus incidencias en el desarrollo de la televisión comunitaria local; dos, se ahonda en la necesidad de entender los modos de organización como asociaciones económicas y sus acciones colectivas (Actividades en Red) como estrategias co-operativas para el trabajo y tres, plantea el papel de la televisión comunitaria como órgano de expresión de las comunidades de esta subregión golpeada por la violencia, la exclusión y la impuesta llegada del desarrollo.

\section{PALABRAS CLAVE.}

Sistema de televisión, canal comunitario, normatividad, trabajo asociado, Oriente antioqueño.

\begin{abstract}
.
This current article, the result of a piece of research, introduces the various situations that the community channels, in the eastern region in Antioquia (Colombia), have to go through. In order to present the results, the text relates three moments: firstly, legal aspects governing the community television system, regulations that have controlled the public television in the country and its effects on the development of the local community television system; in Colombia; secondly, it delves into the need to understand modes of organization such as economic associations and their collective actions (Network Activities) as co-operative strategies for the work, and thirdly, it raises the role of the community television system as an organ of expression of the communities in this sub-region, struck by violence, exclusion, and the imposed arrival of development.
\end{abstract}

\section{KEY WORDS.}

Television System; Community Channel; Regulations; Associated Work, and Eastern Region in Antioquia.

${ }^{1}$ Comunicador audiovisual-docente Investigador. Politécnico Colombiano Jaime Isaza Cadavid Facultad de Comunicación Audiovisual. Grupo de Investigación Enfocar. Medellín, Colombia. Contacto: hilberhenao@elpoli. edu.co

${ }^{2}$ Comunicador audiovisual-docente Investigador. Politécnico Colombiano Jaime Isaza Cadavid Facultad de Comunicación Audiovisual. Grupo de Investigación Enfocar. Medellin, Colombia. Contacto: Johnvergara@elpoli. edu.co

${ }^{3}$ Comunicador audiovisual-Investigador. Politécnico Colombiano Jaime Isaza Cadavid

Facultad de Comunicación Audiovisual. Grupo de Investigación Enfocar. Medellin, Colombia. Contacto: eaortiz@, elpoli.edu.co 


\section{Introducción.}

Una mirada al contexto de la tv comunitaria en Colombia.

La televisión en Colombia ha sido motivo de innumerables debates a nivel nacional, desde el escenario político, económico, jurídico y social, lo cual ha representado gran complejidad en el consenso de propuestas sobre la consolidación de una televisión pública con sentido social.

Por un lado, las diversas coyunturas sociales y políticas generadas por el histórico conflicto armado, incidió de manera significativa en la consolidación un proyecto nacional sobre el servicio de la televisión y sus modalidades (público-privadomixto), lo cual amplió el panorama del debate público nacional en torno al sentido de ser de la televisión pública, su normatividad regulatoria en términos del uso del espacio electromagnético, la infraestructura técnica definida para prestar el servicio televisivo y siendo más importante aún, la representatividad de las comunidades como actor y razón de ser de esta televisión.

En este sentido, María Téllez expresa: "En ese sentido y durante casi quince años, la televisión comunitaria vivió una especie de "limbo juridico", debido a la inexistencia de unas "reglas de juego" para la misma. Es solo con la aparición de la Constitución de 1991 - formulada como una estrategia para responder a la crisis que en todos los ámbitos de la vida social atravesaba el pais, caracterizada entre otros aspectos por un desinterés en los asuntos públicos - donde se introduce el concepto de democracia participativa y donde los medios de comunicación, particularmente la televisión, van a jugar un importante papel en esta nueva relación que se establece entre el Estado y la sociedad civil." (Téllez, 2003)

Sin embargo, la discusión sobre la televisión pública y su futuro, estuvo cimentada en los albores de una iniciativa de cambio de actores de control sobre esta televisión.

Los grupos políticos, sectores económicos de carácter privado y particulares, estuvieron al frente de la administración de canales de televisión, lo cual supuso tanto para el estado y agrupaciones y colectivos sociales y populares interesados en el tema de la televisión pública, repensar el sentido de la televisión pública nacional, sus entes legitimos reguladores y su función social.

Dado este panorama, la discusión de la televisión pública permitió abrir de nuevo el dialogo en diversos aspectos de esta modalidad televisiva, a la par que hacia frente a los insuperables retos normativos que el extenso debate dejaba en el proceso.

A pesar de ello, la concertación y puesta en común sobre la televisión pública, planteaba más inquietudes y complejidades en vez de avances significativos en la consolidación de un proyecto de televisión pública nacional satisfactorio acorde a las necesidades de los operadores de la televisión y las comunidades.

La ley 42 de 1985 como proyecto de gobierno.

La década de los 80's fue crucial para el tema de la televisión pública nacional. Este periodo caracterizado por fuertes tensiones entre diversos sectores politicos, dio pie a una revisión de la televisión nacional, en cuanto se hizo necesaria una revisión exhaustiva a la normatividad que la regulaba, además de comprender diversas 
posturas de las agremiaciones de televisión, quienes empeñaron sus esfuerzos en una apuesta reformista de la televisión pública.

La ley 42 de 1985 nace como una iniciativa que pretendía consolidar la función de la televisión pública, además de la regulación preponderantemente de la programación y el uso del espacio electromagnético, entre otros aspectos relacionados con los sectores y organizaciones articulados a esta iniciativa y al sector de la televisión nacional.

Tal como lo expresa Milciades Vizcaino: "El año de 1984 fue particularmente agitado en cuanto a televisión en el pais. La razón: se discutia un proyecto de ley sobre el manejo y utilización del medio. Pero esto no era suficiente. Fue un Año en que salieron a flote muchas tendencias frustradas en épocas anteriores y los protagonistas salieron a la palestra a buscar escenarios para disputarlas." (Vizcaino, 1992)

Fue durante el periodo de gobierno de Belisario Betancur (1982-1986), que el proyecto de ley 42 ocupó un lugar importante en cuanto el debate nacional sobre una reglamentación de acuerdo a las necesidades actuales y futuras de la televisión pública.

No obstante la discusión de la ley 42 en el escenario nacional, aunque significó grandes avances en la reflexión en materia de programación televisiva, financiación de las agencias y productoras de televisión y el propósito mismo de la televisión pública nacional, no pudo consolidarse como un estatuto nacional de televisión lo cual fue la pretensión inicial. A propósito Milciades Vizcaino dice: "La ley 42 como participación de la "comunidad", como apertura social, como beneficio público o como de interés nacional habia claudicado". (Vizcaino, 1992)

Sin embargo la propuesta de esta ley, aunque representó una iniciativa de convocatoria nacional para la organización de las agrupaciones y agremiaciones de la televisión nacional, fue sin duda una intención de reorganización del sector televisivo y una apuesta hacia la creación y consolidación de una política favorable de la televisión nacional, sus componentes operativos y su función en la comunidad.

Resolución 0433 de la ANTV y el aumento de los problemas de la televisión comunitaria.

El año 2013 representó para los canales de televisión comunitarios del país, un reto de grandes proporciones en cuanto peligraba su existencia como organizaciones. Por un lado la legitimación de la Autoridad Nacional de Televisión (sustituta de la Comisión Nacional de Televisión) como organismo estatal de regulación de la televisión nacional, produjo ciertas incertidumbres frente a las funciones de este organismo así como en la continuidad de las directrices y normativas de la desaparecida Comisión Nacional de Televisión.

Por otro lado, la puesta en vigencia de la resolución 0433 que reglamenta el servicio de televisión comunitaria cerrada sin ánimo de lucro, no solamente produjo un pronunciamiento de las redes organizadas de canales comunitarios y organizaciones prestadoras de este servicio, sino que planteó una gran dificultad en términos de la existencia y la operatividad de la televisión comunitaria a nivel nacional.

Tal como lo expresa el portal informativo alternativaregional.com: "Como el resto en Colombia, actualmente el sistema comunitario vive su propio viacrúsis de cuenta 
de la reglamentación de la TV comunitaria cerrada en el país (Resolución 0433 de la Autoridad Nacional de Televisión ANTV), sobre la cual también han pedido su derogatoria. La citada norma ajustó la nueva reglamentación a un número de 6 mil abonados máximo siendo la anterior de 15 mil, se estableció el pago de compensaciones económicas a la Entidad Nacional ya no por número de usuarios sino por ingresos, situación que entre otras -según ellos-, atenta gravemente contra las condiciones de supervivencia de los sistemas." (Regional, 2012)

En el caso específico de los sistemas comunitarios de la subregión del Oriente Antioqueño, el panorama frente a esta problemática es desolador ya que esta resolución no discrimina localizaciones geográficas ni contextos socioculturales, sin embargo la batalla por la subsistencia y la construcción de prerrogativas de interés colectivo en materia del servicio de televisión comunitario, se ha librado desde tiempos anteriores.

Tal es el caso de la corporación Oriente T.v quien se pronunció frente al proyecto de acuerdo de la CNTV por el cual se reglamenta el servicio de televisión comunitaria: "El proyecto de acuerdo en vez de mejorar las condiciones para la operación de la Televisión Comunitaria, como parte de la Televisión Pública, lo que busca es desmejorar dichas condiciones colocando en peligro la subsistencia de dichos sistemas, pues no fija politicas claras de acceso a recursos y a exenciones que permitan que la televisión comunitaria crezca a través, precisamente, de estrategias como lo son la producción propia." (Oriente T.v, 2012)

Este panorama lo han visibilizado los sistemas comunitarios a nivel nacional, en los subsiguientes pronunciamientos de la organismo estatal (CNTV en esa época), a través de la promulgación del acuerdo 006 de 1999, cuyos lineamientos frente al servicio de televisión comunitaria sin ánimo de lucro, señala tanto para las redes de sistemas comunitarios y las organizaciones de medios comunitarios, una compleja situación en términos de la prestación del servicio de televisión comunitario; una situación que plantea más dificultades que soluciones y una continuidad a una reglamentación desfavorable para estos sistemas comunitarios.

Lo anterior evidencia la iniciativa que ha tenido precisamente esta organización de sistemas comunitarios para hacer frente a las disposiciones reglamentarias del organismo regulador estatal $(A N T V)$, además de señalar que la reglamentación regulatoria de esta modalidad televisiva, ha representado inconsistencias tanto en su formulación así como en sus procedimientos metodológicos de implementación.

En concordancia con los pronunciamientos que han realizado los sistemas de televisión comunitarios del país y siguiendo la línea reformulativa de los estamentos jurídicos promulgados por el ente estatal regulador (ANTV), los canales comunitarios de esta subregión han expresado en su caso particular la verdadera realidad de esta reglamentación.

En entrevista realizada a Oscar Noguera, director del canal comunitario Acuario tv, y perteneciente a la red de sistemas comunitarios Oriente tv, afirmó: "¿Cuál es la realidad de los canales comunitarios en Colombia? Un poco tormentosa.... Los grandes monopolios privados ven en los medios locales una amenaza para su expansión y a través del gobierno y la nueva ANTV cada vez se quieren imponer nuevas reglas que dejen sin herramientas, argumentos, ingresos, y sin forma de mantenerse o subsistir por si solos los sistemas de televisión comunitarios. 
A la fecha intentan crear nuevas normas para pagar por más usuarios, canales codificados y una parte de los ingresos por publicidad que se puedan conseguir a través del canal.” (Regional, 2012)

En tanto respecta a la formulación de propuestas de reforma esta resolución, los diferentes sistemas comunitarios a nivel nacional, han sido claros en los aspectos en que la normatividad los afecta.

Básicamente la resolución 0433 plantea inconvenientes en aspectos como el límite de señales codificadas, autorizaciones para las señales incidentales, la otorgación de licencias, la compensación y pago por el funcionamiento del sistema, el canal de televisión comunitario, derechos de autor, número de asociados, pólizas de cumplimiento, contenidos televisivos y la tecnología y convergencia.

$\mathrm{Y}$ aunque estos aspectos han sido analizados de manera responsable y consciente por parte de las organizaciones de sistemas de televisión comunitarias, es preciso afirmar que las tensiones entre el organismo estatal ANTV y estos sistemas de televisión, se extienden a otras instancias normativas en lo que corresponde al funcionamiento de esta modalidad de televisión.

\section{La TV Comunitaria en el Oriente Antioqueño.}

Caracteristicas de la región.

El oriente antiqueño se ha caracterizado por ser una región de múltiples y variadas características geográficas, tradicionales y culturales donde cada municipio destaca en algún aspecto, no siendo uno más importante que otro, pero en algunos casos prevalecen aspectos desde la historia hasta el presente que han contribuido en el ámbito local, regional y nacional.

El clima en el oriente antioqueño tiene las características de ser cálido, frio y templado en algunas localidades, por lo cual hace que las actividades económicas sean diversas. En algunos casos, la actividad económica de algunos municipios está relacionada con el factor climático.

Sobresale en esta subregión que la mayor parte de la actividad económica está concentrada en la agricultura, conservando aún algunas prácticas artesanales e industrializando paulatinamente los procesos y procedimientos de producción y manufactura. También se encuentra el emplazamiento de empresas industriales y la reactivación del sector productivo manufacturero.

Un aparte interesante como factor socioeconómico de esta subregión es el fortalecimiento del turismo como fuente económica de algunos municipios. En gran medida se debe a que los habitantes de los municipios afectados por el conflicto armado, han retornado a sus lugares de origen y el panorama actual hace visible la efectividad de la intervención estatal en materia de seguridad y apropiación de territorio, facilitando el flujo y la circulación de la población y de visitantes en estos lugares.

Atractivos turísticos como charcos, ríos y cascadas se destacan en estas subregiones, además de obras arquitectónicas coloniales, casa museos, iglesias, parques y lugares públicos que relatan historias de personajes históricos de la vida 
politica y social, entre otros, han consolidado una modalidad de turismo orientado al reconocimiento de la región, las tradiciones y la historia.

No obstante, también prepondera los eventos y festividades tradicionales de cada municipio; algunos de ellos famosos a nivel nacional e internacional, considerándolos como un aspecto interesante en la reactivación y fortalecimiento del sector turístico.

De acuerdo al plan de desarrollo departamental del gobierno de Sergio Fajardo Valderrama se entiende que:

"El Oriente Antioqueño como subregión ha tenido un papel determinante en el desarrollo del Departamento y del pais, lo que la ha posicionado como un territorio estratégico y con amplias ventajas comparativas en cuanto a biodiversidad $y$ recursos naturales, especies únicas de flora y fauna, oxigeno, agua y bosques, potencial turístico y ecoturismo, vocación y capacidad de producción agrícola, ubicación geográfica estratégica, servicios de salud, variedad de climas y un importante desarrollo urbano en múltiples centros de actividad y hábitat."(Fajardo, S, 2012-2015)

Las comunidades de la región antioqueña se informan y se "educan" mediante la oferta de contenidos ofrecidos por los canales de televisión, sean públicos o privados de la región, sin embargo la construcción del imaginario colectivo social que hacen estas comunidades del mundo, obedecen precisamente a una configuración "sesgada" de la información, donde las lecturas de la realidad se construyen bajo nociones bipolares en la interpretación de lo que se dice y se muestra y que a su vez configura la opinión pública.

Los grupos económicos seguirán exponiendo sus verdades a medias, sus intereses de clase. Por eso la comunicación alternativa debe ser la opción para generar nuevos ambientes de medios comunitarios, y de inclusión de las comunidades en pro del desarrollo de la sociedad, de encontrar la identidad y así prestar un servicio a la comunidad.

Es de vital importancia mencionar ciertas propuestas orientadas a la construcción y consolidación de estas iniciativas comunitarias. Una de ellas fue el encuentro de canales comunitarios de Medellín para planear estratégicamente el funcionamiento y asocio de estas propuestas, el cual fue llevado a cabo en el municipio de Girardota en el año 2006. Precisamente este encuentro arrojó varias inquietudes y planteó una revisión del panorama actual de estos proyectos y su permanencia en el presente.

Sin embargo, se hace necesaria y obligatoria una revisión exhaustiva a las iniciativas existentes sobre televisión comunitaria y construcción de espacios de participación comunitaria, donde la mirada investigativa-social de pie al concierto de necesidades y deseos de expresividades, donde el reconocimiento de lo local constituya el eje simbólico y real del hábitat social, donde las dinámicas de interacción socioafectivas de la comunidad tengan espacios de difusión propios y auténticos y en donde la mirada interior y exterior de la vida misma, sea construida a partir de abstracciones e interpretaciones consensuadas, incluyentes y democráticas.

De acuerdo a lo anterior, el análisis de la red de canales comunitarios (Subregión del Oriente de Antioquia) es necesaria en la medida en que se hace obligatorio comprender la perspectiva de la formación especializada en el conocimiento. 
Esto permite trazar una línea comprensiva que sirva como insumo para construir verdaderos escenarios de participación democrática que faciliten la cohesión social de las comunidades entre si y proporcioné elementos teórico-conceptuales que se apoyen en sus construcciones del imaginario social global en sus expresiones comunicativas; es exactamente mostrarse como se ven a sí mismos y como observan, viven y conciben la realidad y el entorno que les rodea.

Una mirado desde los acontecimientos sociales y políticos del Oriente antioqueño.

Este apartado es necesario y pertinente analizar las características geográficas, políticas, sociales y culturales de la subregión del oriente antioqueño como punto de partida para generar una reflexión, no solamente de los medios de comunicación locales comunitarios que esta subregión posee, sino que la revisión a la historia como antecedente, permite encontrar elementos de gran importancia para entender la lógica de los canales comunitarios y su función en las comunidades de acuerdo a los acontecimientos ocurridos.

La subregión del Oriente antioqueño no estuvo ajena a los acontecimientos mundiales; la revolución Agrícola y la revolución Industrial que fueron protagonistas en la Europa del siglo XVII Y XVIII, produjeron un "desarrollo" de la sociedad, ocasionando que las comunidades sean cada vez más numerosas y por lo tanto crezcan y se complejicen sus problemas en términos de sus dinámicas de interrelación social y construcción de estructura de sociedad.

La llegada de estas migraciones al territorio americano, no solamente consistió en el emplazamiento de comunidades en territorio, también propicio la transmisión de pensamientos y valores ideológicos tales como la doctrina fascista, que para aquella época causó una sensación creciente en Europa. Todos estos procesos aparecen ligados al incremento de la población, donde llegan los primeros desplazados europeos por la revolución industrial, quienes se asientan específicamente en el Oriente antioqueño, permitiendo en cierto modo la transmisión de valores culturales, costumbres y tradiciones, que se fueron cohesionando con las prácticas y creencias culturales propias de la subregión.

Para la segunda parte del siglo XIX, inicia la colonización del café, apareciendo distritos agrarios administrados por los militares que participaron en las guerras civiles colombianas, y que por la falta de presencia del estado, fueron apropiados. De este modo, aparece un modelo de empoderamiento centralista, que se reproduce paulatinamente en gran parte del territorio nacional y en cierta medida es posible considerar que la principal razón del conflicto hasta la actualidad es la apropiación y tenencia de la tierra.

En la década de los 50`s la región es golpeada por la violencia partidista, que se caracterizó por la confrontación armada de los partidos políticos tradicionales. Tarazona y Álvarez afirman: "En los siguientes años, la guerra bipartidista dejó grandes secuelas como la polarización política entre la sociedad colombiana, lo cual conllevó al establecimiento de un periodo caracterizado por la alternancia de gobiernos liberales y conservadores" (Tarazona \& Álvarez, 2001) 
En la década de los 70`s, ocurre un fenómeno de activación industrial en la subregión del Oriente antioqueño, mediante la presencia de las empresas hidroeléctricas ISA, ISAGEN y EPM (Carvajal, 2009); empresas que con el apoyo del estado generan confrontaciones entre la población y la industria hidroeléctrica en desarrollo, además hubo una confrontación entre estas empresas por el control de territorios estratégicos de explotación hídrica.

Existe un caso específico en el municipio de San Carlos, localidad que pertenece al Oriente antioqueño, el cual genera aproximadamente el 33\% de la energía del país que inicialmente se planteaba para abastecimiento y consumo interno de la población del municipio y parte de la subregión. (Enfocar, 2014)

La presencia de empresas como Argos y las empresas de explotación hidroeléctrica, lograron posicionarse en la subregión, ocasionando gran inversión de proyectos hidroeléctricos con el apoyo del gobierno nacional, por ejemplo en el municipio de san Carlos la inversión se magnificó hasta el punto de tener actualmente cuatro centrales hidroeléctricas.

La llegada de estos grandes proyectos económicos que contaron con el aval estatal para la explotación de los recursos naturales, produjo así un desplazamiento de las comunidades de los municipios de San Carlos, San Rafael y San Roque específicamente, sitios elegidos para la construcción de las centrales hidroeléctricas, y cuyo desplazamiento fue legitimado por el estado.

Esta realidad y otras problemáticas sociales, conllevó a la convocatoria y organización de la comunidad, mediante lo que se conoce como el movimiento cívico de los 80 's, organización popular que sostuvo confrontaciones politicas con las empresas hidroeléctricas y algunas instituciones del estado. (Olaya, 2012)

A raíz de esta problemática entre otras que atañen a la realidad social y política de país, el movimiento cívico, cuyo objeto de lucha era los beneficios justos para las comunidades afectadas por el impacto de los megaproyectos hidroeléctricos, continuó su trabajo en la defensa de algunos territorios de la subregión del Oriente antioqueño, donde la industria hidroeléctrica hizo mayor presencia, hasta la década de los 90's, periodo caracterizado por las confrontaciones armadas entre las guerrillas de las FARC y el ELN y los paramilitares.

Cabe aclarar que durante el periodo del Frente nacional (Acevedo Tarazona \& Castaño Alvarez, 2001) se impulsó la violencia, en gran parte del territorio nacional, y específicamente en la subregión del Oriente antioqueño.

Durante la década de los 80`s el conflicto se caracterizó por la aparición de actores armados como los paramilitares y la construcción de una relación entre la policía y el narcotráfico, siendo este último quien financiaría la violencia en la región; el inició de esta acción invasiva tuvo como fachada el despojo de la guerrilla del territorio, siendo en realidad un desplazamiento masivo de campesinos de la zona. (Verdad abierta, 2014)

Ya en la década de los 90's los campesinos retoman sus actividades ocupándose de la agricultura, a la par que se reconfigura un nuevo escenario del conflicto, donde se pretende despojar a la guerrilla del territorio, a la vez que los paramilitares 
junto a las fuerzas militares avanzan de manera violenta contra la población como una forma de generar terror y controlar la región, ocasionando grandes pérdidas humanas y un éxodo de campesinos que redujo significativamente la población en gran parte de algunos municipios de la subregión.

Perspectiva desde la necesidad mediática.

Las construcciones de la realidad social inmediata, la identificación con los lugares de origen, el desarrollo vivencial individual y colectivo de sus habitantes y la mirada elaborada colectivamente sobre el mundo que rodea a las comunidades, tan solo ha resultado ser un palimpsesto de lo que ha sido "una realidad global, incluyente y justa de la vida, de los sucesos de importancia social, politica, económica y cultural" que entraman el tejido social nacional.

Y es preciso que las comunidades asentadas a lo largo y ancho de la región, con sus multiplicidades culturales y tradicionales acentúen su voz, sus expresiones particulares mediante sus tonos y matices particulares de evidenciar sus problemáticas y necesidades, éxitos y fracasos y ante todo, presentar sus realidades inmediatas y re-presentar el contexto nacional; es la interpelación a la interpretación del mundo desde la mirada propia de las comunidades.

A propósito de esto, Guillermo Orozco menciona:

"Por otra parte, la televisión comunitaria, como se le designa en Colombia, permite concentrarse en lo local e intercomunicar, pero sobretodo representar e incluir a esas audiencias olvidadas o excluidas de las otras pantallas. A veces como televisoras de servicio público, a veces como macroinstituciones que se roban la señal de satélite y hacen extensiva la posibilidad de disfrutar hasta de programación internacional a la comunidad audiencia que las cobija, las televisiones alternativas están cargadas de futuro y esperanza en américa latina” (Orozco, 2001)

Entonces se replantea precisamente el papel de la televisión vista como un agente re-socializador de las comunidades y se concibe como elemento de construcción del imaginario colectivo comunitario cargado de una potencialidad creadora de sentido propio, en donde la televisión elaborada en el seno de su universo social, narra sus cotidianidades, reconociendo su territorialidad, su ciudadania, su pertenencia y existencia en el tiempo y el espacio y permitiendo amalgamar las múltiples voces y miradas de sus habitantes.

De este modo, se ha supuesto que esta modalidad televisiva ha venido cumpliendo un papel crucial en el desarrollo social de las comunidades; desarrollo que en suma medida se alimenta del interés colectivo de las mismas comunidades por expresarse y versen a sí mismas representadas mediante sus expresiones y narrativas particulares.

"Producir uno mismo sus productos mediáticos implica tener la oportunidad de crear las propias imágenes de sí mismo y del entorno; implica poder recodificar la propia identidad con signos y códigos elegidos por uno mismo, irrumpiendo así en la aceptación pasiva de identidades impuestas por sujetos externos; implica convertirse en el relator de la propia historia y recobrar asi la voz propia; implica reconstruir el autorretrato de la comunidad y sus culturas" (Rodríguez, 2009) 
Desde esta primera instancia, descripción desde la importancia de la territorialidad y la representación de esta, es la que hace posible que esta modalidad televisiva y sus construcciones cargadas de riqueza expresiva y ante todo de necesidades de re-presentación social y cultural mediante la figuración mediática propia, continúe siendo motivo de indagaciones profundamente teóricas a la vez que plantea nuevos horizontes de trabajo colectivo de estas comunidades.

\section{Metodologia.}

Para el desarrollo del presente texto, se realizaron:

Dos jornadas subregionales de Canales comunitarios, lideradas por el grupo Enfocar (2012-2013).

Se realizaron varias entrevistas grupo focal, con actores clave de la region.

En esta dinámica y se adelantaron entrevistas individuales que dieran cuenta de la historia, impacto y logros de los canales comunitarios en la región.

Rastreo bibliográfico y normativo sobre el tema canales comunitarios y la realidad del conflicto en la región.

Ahora bien, Para presentar los resultados el texto, se definieron tres momentos.

- Descripción e algunos aspectos jurídicos, normativos que ha regido a la televisión pública en el país y sus incidencias en el desarrollo de la televisión comunitaria local

- Se ahonda en la necesidad de entender los modos de organización como asociaciones económicas y sus acciones colectivas (Actividades en Red) como estrategias co-operativas para el trabajo y

- Para finalizar, se plantea una reflexión en torno al papel de la televisión comunitaria como órgano de expresión de las comunidades de esta subregión golpeada por la violencia, la exclusión y la impuesta llegada del desarrollo.

\section{Resultados - discusiones.}

La televisión comunitaria-Necesidades y fortalezas formativas desde lo académico, investigativo y operativo. Oriente Antioqueño.

La iniciativa de hacer televisión comunitaria y crear medios de comunicación locales alternativos, han estado ligadas a consolidar el trabajo y todas aquellas actividades operativas (todo lo relacionado con la manipulación de equipos técnicos y la producción de la imagen de acuerdo a cánones de calidad), mediante el fortalecimiento de sus capacidades creativas y procedimentales y la construcción de conocimiento en áreas de trabajo específicas que sirven como insumo teóricopráctico en el ejercicio de la producción televisiva y la construcción de ejes comunicativos que permitan el trabajo co-rresponsable con la comunidad.

A propósito María José Román dice: “A pesar de la creciente profesionalización de estas organizaciones, y sus esfuerzos en el fortalecimiento de redes alternativas, éstas organizaciones siguen ubicadas en las márgenes de la cultura mediática; entre las dificultades que enfrentan se encuentran la falta de una infraestructura cultural institucional de apoyo (educación, fondos, políticas públicas)” (Román, 2009) 
El largo camino que enfrenta la televisión comunitaria, se ve reflejado en este paradigma de carencias y a su vez en la misma calidad de sus productos televisivos. Y aunque tanto programas de televisión así como diversos productos audiovisuales y mediáticos en general han sido elaborados mediante interpretaciones teóricas y aprendizajes desde lo experimental y vivencial, sin lugar a duda existe un sesgo generacional en la preparación académica formal en diversos campos y procesos de producción de esta televisión.

Precisamente el primer encuentro departamental de canales comunitarios realizado en 2012, no solamente permitió acercar a diversas asociaciones y canales comunitarios de Antioquia, sino que mediante la aplicación de un instrumento investigativo, se pudo constatar varias suposiciones que se han venido planteando aquí:

De la información recolectada a través de aplicación de encuestas encontramos por un lado que algunos canales comunitarios y asociaciones si bien han recibido capacitaciones en aspectos técnicos (manejo de cámaras, equipos de edición de video, entre otros), la mayoria de los canales tienen enormes necesidades en ser capacitados en aspectos técnicos y operativos, asi mismo, que la forma de hacer red es a través de capacitación de personal y la manera de mantenerse en el medio se hace más por la gestión propia, autónoma de quien o quienes asumen el reto de sostener dichos canales (Enfocar, 2012)

Estos y otros datos permiten comprender que la televisión comunitaria no solamente se consolida en la iniciativa de hacer una televisión "más propia"; una televisión de carácter social hecha mediante esfuerzos colectivos por mostrar sus propias expresividades, sino que se hace evidente que sus propuestas deben estar enmarcadas en la calidad de sus imágenes y transmisiones, en la capacitación de su capital humano, en el fortalecimiento de sus vínculos con otros canales y asociaciones que persiguen los mismos propósitos y ante todo en la consolidación de su propuesta televisiva ante la misma comunidad, consolidación entendida en términos de aceptación de la recepción televisiva y la generación de contenidos propios de la comunidad que por ende afecta de cierta u otra forma la permanencia y el funcionamiento de un canal de televisión propiamente de esta modalidad.

Precisamente este panorama indica que por medio de oportunidades de acceso a la educación superior y a la formación especializada en campos específicos de la televisión, es posible consolidar aquellos esfuerzos que la televisión comunitaria realiza para mantener en pie sus iniciativas.

A propósito de esto, el plan de desarrollo departamental (Antioquia-Colombia) expresa lo siguiente:

"Ofrecer a las distintas subregiones del Departamento la posibilidad de contar con un recurso humano calificado en las Instituciones de mayor calidad, en los diversos niveles de la educación postsecundaria, (formación para el trabajo, técnica profesional, tecnológica, universitaria y de posgrado) y de acuerdo con las potencialidades y necesidades de las regiones" (Fajardo, S, 2012-2015)

Es la formación académica e investigativa que la institución educativa de la mano con la puesta en marcha de planes de gobierno y la misma disposición hacia el trabajo que asociaciones y canales comunitarios manifiestan mediante sus deseos 
en fortalecer su quehacer, lo que posibilita los cambios orientados hacia una verdadera transformación; transformación hacia una nueva televisión.

Acerca de los sistemas de televisión, los canales comunitarios y el trabajo asociado.

En la subregión del oriente antioqueño no cabe duda alguna que el conflicto armado colombiano, emplazó parte de su fuerza bélica en gran parte de sus municipios, dejando como resultado la destrucción del tejido social, el desarraigo y un éxodo de la población civil que resulta ser una fórmula común en cualquier conflicto armado, sea cual sea su naturaleza.

Las disputas por el control de territorios por parte de la guerrilla y luego la presencia de grupos paramilitares en articulación con la presencia militar colombiana para retomar dichos territorios y detener la avanzada subversiva, fueron las causas de esta contienda.

Haciendo énfasis en el papel de los medios comunitarios frente a esta confrontación, estos constituyeron un eje estratégico para la difusión de información desde ambos mandos en disputa.

Pero esta función fue ejercida bajo una autoridad de naturaleza coercitiva impuesta por parte de los actores armados, produciendo así un rezago en la producción y difusión de contenidos de los medios locales y en parte limitando el funcionamiento de estos.

De acuerdo a lo anterior, la publicación de un informe periodístico frente al papel de los medios comunitarios en el conflicto armado en esta subregión del departamento resalta: "En estos municipios, los proyectos de comunicación nacen como mecanismos de cohesión cultural, en los que el conflicto, pese a que los afecta de forma directa, no tiene cabida por no hacer parte de la propuesta comunitaria" (Lina \& Isaza, 2005)

De esta forma, los medios locales no solamente limitaron la producción y difusión de contenidos, sino que prácticamente sus actividades como medios de expresión comunitarios se vieron restringidas, a la vez que estos mismos medios realizaban un esfuerzo en contra de una legitimación impuesta por la fuerza sobre la presencia y acción de estos grupos en las comunidades y en los mismos medios y sistemas comunitarios.

Esta contextualización del papel de los medios locales comunitarios en el conflicto armado que tuvo lugar en el Oriente de Antioquia, es tan solo una intención de comprender sus funciones ante esta realidad vivida y analizar las posibles consecuencias que produjo este conflicto en la continuación de la actividades que cada medio local comunitario se había propuesto desde su constitución y consolidación como órgano de expresión de la comunidad.

Comprender el fenómeno de la televisión comunitaria ha supuesto contemplar diversas miradas y concepciones; al hablar de ello, existe la tendencia de pensar en canales de televisión locales donde las temáticas suelen ser relatos de las mismas comunidades con sus personajes, lugares y acontecimientos y también se suele considerar en programación televisiva de canales de televisión regionales, nacionales y extranjeros (oferta de paquetes de canales de televisión por cable o satelital). 
Y aunque lo anterior es cierto, los sistemas de televisión comunitarios tienen una función específica y van más allá de la simple comprensión de que son lugares y personas que ofertan servicios para adquirir planes de consumo televisivo y suscripción a diferentes servicios que ofrecen algunos de estos sistemas, por ejemplo cooperativas de ahorro, servicios exequiales, entre otras diversas y variadas formas de generación de ingresos económicos.

Por un lado, los sistemas de televisión se crean a partir del eminente boom de las llamadas antenas parabólicas que tuvieron auge paulatinamente en diversas comunidades diseminadas a lo largo y ancho del territorio nacional.

A propósito de lo anterior, el abordaje que hace María Téllez frente a este fenómeno resulta de gran pertinencia en su comprensión por lo cual afirma que: "Esta historia en Colombia se inicia a comienzos de los años 1980 y en su aparición se conjugan razones tecnológicas relacionadas con el incremento del uso del satélite para la transmisión de información y el auge de la oferta televisiva en Estados Unidos, con el consecuente desarrollo y disminución de los costos en equipos de recepción y distribución de la señal audiovisual” (Téllez, 2003).

Y por otro lado, a razón de las posibilidades tecnológicas que se ofreció en materia de consumo televisivo, las antenas parabólicas empezaron a consolidarse en el ámbito industrial, conformándose como empresas prestadoras del servicio de televisión por cable y más adelante incursionando en la televisión satelital, sin embargo la figura de agremiación económica ha sido compleja en la medida en que algunos de estos sistemas no han prosperado a razón de diversos factores que afectan su sostenimiento económico, lo cual hace que no sean viables.

Precisamente frente a la complejidad en la financiación y auto sostenimiento de estos sistemas de televisión y en parte en la concepción de una televisión de carácter pública, aparecen los sistemas de televisión comunitarios como una forma asociativa que nace de las necesidades de las comunidades en el emprendimiento de iniciativas de organización.

Al permitir la Constitución Politica de Colombia el derecho a la libre asociación, en el caso de la conformación de sistemas de televisión comunitaria se unen personas denominadas naturales que por lo general pertenecen a un barrio, localidad o municipio. Los modelos de asociación se basan en la forma de organización de las Juntas de Acción Comunal (JAC). El resultado que otorga la junta es el de asociaciones, corporaciones o ligas. (Parga, 2012).

De este modo, los sistemas de televisión comunitarios han logrado un avance significativo en la medida en que la organización comunitaria ha logrado consolidarse, afrontando diversas dificultades como la financiación y generación de recursos económicos de subsistencia, la adaptación organizacional y de prestación del servicio de televisión comunitaria de acuerdo a las disposiciones regulatorias de los organismos estatales, entre otros de gran importancia y que pueden sumarse a la larga lista de necesidades que estos sistemas comunitarios han manifestado desde tiempo atrás.

Sin embargo la necesidad imperante que ha afrontado estos sistemas de televisión comunitarios desde sus inicios, siempre ha sido velar por la comunidad, a través de su filosofia e idiosincrasia, como órganos de expresión de lo local y para lo local, 
atribuyendo gran valor a la labor creciente y expansión de la experiencia de trabajo otros territorios y comunidades.

Tal como lo manifiesta el estudio realizado por Natalia Forero: "En la actualidad Colombia cuenta con más de 700 comunidades organizadas ya sean asociaciones, corporaciones, o ligas y todas estas han nacido de necesidades sentidas de conformar un medio de comunicación" (Parga, 2012).

Al haber dado un significado a los sistemas comunitarios como entes autónomos existentes bajo la figura de asociaciones y corporaciones prestadoras del servicio de televisión comunitario y con responsabilidad social y jurídica, la creación de canales de televisión comunitarios, no solamente hace parte de la iniciativa que emprenden los sistemas comunitarios, sino que obedece precisamente a la producción de contenidos televisivos de carácter autóctono y visibilización de aspectos locales.

No obstante, aunque cada sistema de televisión comunitario, específicamente de la región del Oriente Antioqueño, es poseedor de razones particulares y circunstancias sociales, jurídicas e históricas concretas, la mayor parte de ellos conservan ciertas similitudes.

La siguiente afirmación evidencia que: Los canales en si se crean porque hay un sistema de televisión, entonces se crea el sistema de televisión para prestar el servicio a la comunidad, luego la ley dice que ese servicio debe de generar una contraprestación para la comunidad y es un canal de producción propia, entonces en muchas partes se ha creado por la propia convicción pero también porque la ley lo ha exigido. (Duque, 2013)

De acuerdo a lo anterior, según la encuesta realizada a los 13 sistemas comunitarios del Oriente Antioqueño sobre lo que cada canal comunitario considera como razones esenciales para el funcionamiento del servicio de televisión comunitaria, así como contribuciones de los sistemas de televisión a la construcción de la imagen positiva del municipio.

La mayoría de los encuestados respondieron de 1 a 2 razones, obedeciendo precisamente a necesidades y particularidades que tienen cada uno de los canales comunitarios a los que representan.

Una constante fue la relación que se hacía a la Ley 0433 que propone la ANTV (organismo estatal que regula la televisión en Colombia); según esta ley, se exige la creación de los canales de televisión de carácter comunitarios en el país.

Cabe anotar que los canales comunitarios son espacios centralizados propios de los sistemas comunitarios, regidos tanto por la filosofia y valores organizacionales de cada sistema, así como su naturaleza jurídica que para el caso de los sistemas de televisión comunitarios, según la disposición reglamentaria de la ANTV es televisión comunitaria sin ánimo de lucro. (Por el cual se reglamenta parcialmente el servicio de televisión comunitaria cerrada sin ánimo de lucro, 2013)

Tal como expresa la corporación Oriente tv:

"A finales de la década de los ochenta y principios de los noventa, las comunidades locales y subregionales, con el objetivo de mejorar las condiciones de accesibilidad 
a la televisión y captar señales regionales, nacionales e internacionales a través de Antenas Parabólicas, se organizan en entidades sin ánimo de lucro, dotadas de personería jurídica y regidas para aquél entonces por normas que establecian una serie de condiciones minimas para organizarse a través de sistemas de Antenas Parabólicas locales, vigiladas y contraladas por las Gobernaciones departamentales" (Oriente T.v, 2012)

Dado esto, sistemas comunitarios de televisión han apelado al trabajo cooperativo, por un lado dadas las exigencias normativas de los entes reguladores estatales y por otro, desde la necesidad de satisfacer las comunidades a través de la oferta de la variedad de contenidos televisivos.

La red de canales comunitarios- propuesta de una dimensión articulada de la televisión local.

La importancia de las asociaciones, colectivos sociales y culturales y canales comunitarios es la afinidad con respecto al sentido de trabajo comunitario que poseen; es la importancia social que dan a su trabajo desde la actividad comunicativa mediática, la cual presenta un gran interés en el fortalecimiento de su labor mediante la producción televisiva constante y de calidad, a la vez que afiance sus motivaciones en dichas actividades y legitime su obra ante la comunidad.

No obstante, el trabajo colectivo se hace necesario ya sea mediante labores coproducidas directamente enfocadas en producción y realización televisiva, prestamos de equipo técnico y personal laboral hasta capacitaciones en el ámbito de operación y manejo técnico de equipos.

Precisamente, en la primera experiencia del encuentro departamental de canales comunitarios realizado en el Politécnico Colombiano Jaime Isaza Cadavid, se plantearon varios puntos que sugieren desde un panorama de necesidades insatisfechas hasta ahora, una serie de pautas de lo que se entiende por construcción y trabajo en red:

Datos arrojados mediante el análisis y la interpretación de grupo focal (Instrumento investigativo aplicado en la realización del primer encuentro departamental de canales comunitarios), encontramos que existen alianzas entre emisoras locales $y$ canales de televisión comunitarios, asi mismo, en alguna ocasión hubo experiencias de intercambio de programación entre canales comunitarios y que se concibe a la red como facilitadora del trabajo colectivo en cuanto a intercambio de personal de trabajo, equipo técnico, etc (Fierro \& Vergara, 2012); (Enfocar, 2012)

Al igual que estas afirmaciones, existen otras que evidencian de manera significativa la concepción de la Red de Canales Comunitarios, sus funciones en términos de la articulación de esfuerzos colectivos de las diversas iniciativas que se dan en la región y el sentido funcional y mediador de facilitar el intercambio de experiencias de esta televisión entre sus productores y usuarios, es decir propiamente la creación de escenarios de producción colectiva y co-responsable entre los miembros de cada comunidad particular.

En sí mismo, es la consolidación de la red como el eje articulador de las diversas experiencias comunicativas-televisivas la que permitirá el trabajo colectivo en su búsqueda de facilitar las interacciones entre las iniciativas existentes y por 
ende cohesionar las diferentes propuestas de fortalecer sus áreas de trabajo desde la formación académica e investigativa hasta las posibilidades extender sus propuestas hacia otras comunidades ubicadas en la periferia para hacer posible el intercambio de experiencias y construir lazos desde el trabajo en común y por ende lazos fraternales.

Precisamente en el caso de la experiencia de trabajo en red de los canales comunitarios de la subregión del Oriente antioqueño, las actividades colaborativas están orientadas al intercambio de programación de cada canal comunitario, además de asistir con personal técnico y humano, algunas eventualidades que se presentan en las localidades.

Sin embargo sobresale un aspecto de gran importancia para los sistemas de televisión y es la planificación de acciones estratégicas en conjunto con respecto a la normatividad que rige a la televisión comunitaria nacional.

Esto evidencia que el trabajo en red no solamente se limita al intercambio de contenidos televisivos, equipo técnico y humano; las actividades que precisan acciones en términos jurídicos constituyen un insumo necesario para afianzar y potencializar el trabajo colaborativo de estos sistemas de televisión.

Esto constituye la puesta en marcha de acciones colectivas ya sean para intercambio de productos televisivos o para hacer frente colectivamente a las disposiciones jurídicas en materia de televisión comunitaria.

Sin embargo la orientación que persigue la agrupación de sistemas de televisión de la subregión del Oriente de Antioquia (denominada corporación Oriente tv), es el intercambio de experiencias de trabajo, que permita el crecimiento y desarrollo de cada sistema de televisión, siendo lo anterior el engranaje necesario para consolidar el trabajo asociativo que han venido realizando y pretenden continuar cada uno de ellos.

El sentido comunitario-La construcción de tejido social en lo local.

Cada sociedad posee rasgos particulares en cuanto son poseedoras y constructoras de valores enmarcados en ámbitos como la cultura, la política, la economía, entre otros. No obstante las concepciones sobre lo comunitario han ido más allá del simple significado utilizado para designar grupos de personas asentadas en un lugar específico y aunque pueden surgir momentos circunstanciales para denominar sea grupos humanos o prácticas colectivas de diversa índole, como expresiones comunitarias, es necesario mencionar que existen condiciones estructurales e idiosincráticas que autentifican lo comunitario en las comunidades.

Un primer acercamiento a la noción de comunidad señala que la definición de "comunidad" como lugar del lazo, de la identidad, de la permanencia, de las relaciones naturales y voluntarias emerge no sólo en el sentido corriente con que se emplea el término, sino también en distintas áreas de las ciencias humanas (Hernández, 2011).

Lo anterior indica que los usos del concepto comunitario son diversos, de acuerdo a las áreas de estudio que se emplean para su definición. 
Sin embargo elementos como la construcción de lazos sociales, la identidad y la apuesta por la permanencia en el tiempo y espacio, constituyen características que permiten en primera instancia comprender la noción de comunidad desde sus elementos constitutivos, sin que estos sean irreductiblemente condiciones estrictas.

No obstante, en el panorama aparecen aspectos ligados a sus dinámicas de interrelación social y que se materializan en estructuras y formas de organización social y acciones colectivas con fines mancomunados que nacen en el seno de las comunidades y cuyos beneficios esperados son para sí mismos.

Tal como plantea Guillermo De La Peña: "La cuestión analítica fundamental es la capacidad de estos grupos de proyectar una solidaridad fundada originariamente en vínculos personalizados y afectivos hacia la participación estratégica y la representación diferenciada en ámbitos societales" (De la Peña, 2000)

Por un lado la comunidad es expresada como un conjunto de individuos con características específicas que permiten ser diferenciadas con respecto a otras comunidades, pero por otro, se reflejan acciones organizadas y colectivas que acentúan el valor de la comunidad en términos de grupos sociales que construyen y comparten valores simbólicos y que poseen dinámicas sociales particulares que afianzan los vínculos socioafectivos y orientan las acciones colectivas en porvenires de la comunidad.

Entonces lo comunitario puede entenderse como acciones de organización cooperativas, en donde las actitudes de sus miembros están dotadas de un amplio sentido de colaboración mutua y que la reciprocidad de tales acciones, cualesquiera que sean, se comportan como beneficios para el grupo social (comunidad).

Precisamente la televisión comunitaria aunque ha cumplido con fines orientados al sostenimiento de los sistemas de televisión como entes económicos, ha realizado una apuesta al fortalecimiento de las comunidades desde la consolidación de órganos de expresión como los medios comunitarios; medios que han permitido resaltar aspectos como la cultura, las tradiciones y costumbres que poseen cada una de ellas.

Por ello, el sentido de lo comunitario puede leerse como un acto colectivo que está orientado al fortalecimiento de los vínculos sociales que las comunidades poseen y que han conservado como valores expresados en prácticas sociales y culturales, y por otro, los medios comunitarios, precisamente se han convertido en los portavoces de estos valores y prácticas y que constituyen la base estructural de estos actos colectivos; acciones que al fin y al cabo son reciprocas en la medida en que existe una interacción dialógica entre los canales comunitarios y la comunidad.

\section{Conclusiones.}

Hoy, las asociaciones y corporaciones de sistemas comunitarios han continuado impulsando el desarrollo de la televisión comunitaria, en la medida en que el trabajo asociativo ha constituido una base sostenible de gran parte de los sistemas de televisión comunitarios.

Desde la existencia y consolidación de los sistemas comunitarios, el trabajo asociativo ha constituido más que una iniciativa de integración e interrelación entre estos 
mismos, ha servido como figura de potencialización de sus propuestas de trabajo colectivo en diversos ámbitos operativos del quehacer televisivo y como instrumento legítimo de apoyo ante las diversas dificultades en aspectos financieros y jurídicos.

No obstante el trabajo asociativo fue posible lograrlo debido a la necesidad inicial de agrupar y acercar las comunidades y organizaciones de sistemas de televisión sin ánimo de lucro para acceder a varios aspectos esenciales de las comunidades como la cultura, el deporte, la recreación, la convivencia, entre otros y partir de estos crear contenidos de acuerdo a las necesidades de las comunidades.

Los sistemas comunitarios de la subregión del Oriente antioqueño han consolidado su trabajo colectivo en la corporación Oriente tv; organización que agrupa a los sistemas comunitarios de esta subregión y quien a través del intercambio de programación y contenidos televisivos y asistencia en materia administrativa y jurídica a los sistemas de televisión miembros, ha permitido visibilizar a sus comunidades y constituir un verdadero modelo de trabajo asociativo.

A finales de la década de los ochenta y principios de los noventa, las comunidades locales y subregionales, con el objetivo de mejorar las condiciones de accesibilidad a la televisión y captar señales regionales, nacionales e internacionales a través de Antenas Parabólicas, se organizan en entidades sin ánimo de lucro, dotadas de personeria juridica... Dichas comunidades no tenian acceso a esas señales, por cuanto el Gobierno Nacional no era y ni ha sido capaz de facilitar que la población Nacional tenga acceso a aquellas, lo que a todas luces se convertia en una limitante para acceder a la cultura, recreación, diversión e información de un mundo que para la época ya había dado los pasos para la completa globalización. (Oriente T.v, 2012)

En líneas anteriores de este texto, se destacó el trabajo asociativo de los canales comunitarios en el intercambio de programación y apoyo administrativo y jurídico a los sistemas comunitarios de gran parte de la subregión del Oriente antioqueño.

La mayor parte de los sistemas comunitarios hacen parte de la corporación Oriente tv y Conmutv; siendo la corporación Oriente tv la que ha consolidado su labor en el fortalecimiento de los canales comunitarios en materia de producción televisiva, intercambio de contenidos, orientación y capacitación del personal laboral, entre otras actividades que están orientadas al fortalecer los sistemas comunitarios miembros. 


\section{Referencias Bibliográficas.}

Acevedo Tarazona, A., \& Castaño Alvarez, S. (2001). "El Frente Nacional Una reflexión histórica de su legitimidad política". Revista Ciencias Humanas(28). Recuperado el 1 de 05 de 2014, de utp.edu.co: http:/ / www.utp.edu.co/ chumanas / revistas / revistas/rev28/acevedo.htm

Balbin , J., \& Insuasty Rodriguez, A. (2010). Las Victimas en Contextos de Violencia e Impunidad: Caso Medellin. Medellin: Instituto Popular de Capacticación.

Balbin, J., \& Insuasty Rodriguez, A. (2009). Victimas, Violencia y Despojo. Medellín: Litoimpacto.

Carvajal, E. M. (15 de 09 de 2009). http://www.pnud.org.co. Recuperado el 16 de 04 de 2014, de http://www.pnud.org.co: http://www.pnud.org.co/sitio. shtml?x=59398\#.VCTYyhaaSSp

De la Peña, G. (2000). La modernidad comunitaria. Desacatos-Numero 3, 20.

Duque, P. A. (25 de 05 de 2013). Canales comuntarios del Oriente Antioqueño (Colombia). (Enfocar, Entrevistador)

Enfocar. (2012). Primer encuentro departamental de canales comunitarios de Antioquia. Medellín: Politécnico Jaime Isaza Cadavid.

Enfocar. (2 de 10 de 2014). Desarrollo desplazamiento y violencia. Caso San Carlos. Antioquia. Colombia. Obtenido de soundcloud.com/kavilando/sets/desarrollodesplazamiento-y:https:// soundcloud.com/kavilando/sets / desarrollodesplazamiento-y

Fajardo, S. (2012-2015). Plan de desarrollo de Antioquia. Medellín.

Fierro, H. H., \& Vergara, J. F. (2012). Primer encuentro departamental de canales comunitarios. Medellín.

Hernández, S. (2011). El pensamiento de la comunidad: Un aporte para pensar las relaciones entre sujeto, espacio y ciudad. Enfoque XIII, 45-56.

Lina, M., \& Isaza, M. (2005). Una mirada al oriente, sus medios, su gente. Fundación para la libertad de prensa, págs. 3-8.

Olaya, C. H. (2012). Nunca más contra nadie. En C. H. Olaya, Nunca más contra nadie (pág. 61). Medellín: Cuervo editores.

Oriente T.v, C. (2012). https://www.facebook.com/pages/Oriente-TeVe. Recuperado el 28 de 03 de 2014, de https:/ / www.facebook.com/pages/Oriente-TeVe:https:// www.facebook.com/pages/Oriente-TeVe/182497748518723 
Orozco, G. (2001). Televisión, audiencias y educación. Colombia: Grupo editorial Norma.

Parga, N. F. (18 de 11 de 2012). Análisis de la incidencia de la Televisión Comunitaria en Colombia en la conformación de espacios de participación ciudadana durante el periodo de 1995-2010. Tésis de pregrado. Bogotá D.C, Bogotá, Colombia: Repositorio institucional Edocur.

Por el cual se reglamenta parcialmente el servicio de televisión comunitaria cerrada sin ánimo de lucro, Resolusión 0433 (Autoridad Nacional de Televisión (Colombia) 15 de Abril de 2013).

Regional, A. (15 de 10 de 2012). www.alternativaregional.com. Recuperado el 23 de 04 de 20144, de www.alternativaregional.com: http://www.alternativaregional. $\mathrm{com} /$ television-comunitaria-david-contra-goliat-i-parte

Rodríguez, C. (2009). De medios alternativos a medios ciudadanos: Trayectoria teórica de un término. Folios, 13.

Román, M. J. (2009). Mirar la mirada: Para disfrutar el audiovisual alternativo y comunitario. Folios, 144.

Tarazona, A. A., \& Álvarez, S. C. (2001). El Frente Nacional Una reflexión histórica de su legitimidad politica. Recuperado el 15 de 04 de 2014, de http://www.utp. edu.co: http://www.utp.edu.co/ chumanas/revistas/revistas/rev28/acevedo. htm

Téllez, M. (2003). La televisión comunitaria en Colombia: Entre la realidad y la utopía. Bogotá: Ministerio de cultura; Comisión Nacional de Televisión.

Verdad abierta, O. (08 de 02 de 2014). www.verdadabierta.com. Recuperado el 16 de 04 de 2014, de www.verdadabierta.com: http:/ /www.verdadabierta.com/ procesos-de-paz/farc/5236-las-farc-cosecharon-odios-en-el-oriente-antioqueno

Vizcaino, M. (1992). Los falsos dilemas de nuestra televisión:Una mirada tras la pantalla. En M. Vizcaino, El estado y la televisión:Una experiencia que quedó atrás: La ley 42 (págs. 38,39). Bogotá: Grupo editorial 87.

\section{Nota:}

${ }^{1}$ Artículo fruto de la investigación "La televisión comunitaria en Antioquia: Reconocimiento de su genealogía operativa y su función social para la construcción de la red de canales comunitarios de la región" finalizada en el año 2014, donde los autores del presente texto participaron en calidad de investigadores, financiada por el Politécnico Jaime Isaza Cadavid. Medellín, Colombia. 